\title{
A Novel Model Predictive Control for Stability Improvement of Small Scaled Zero-inertia Multiple DGs Micro-grid
}

\author{
Abdulrahman J. Babqi ${ }^{1 *}$ \\ ${ }^{1}$ Department of Electrical Engineering, College of Engineering, Taif University, P. O. B. 11099, Taif 21944, Saudi Arabia \\ * Corresponding author, e-mail: ajbabqi@tu.edu.sa
}

Received: 10 September 2021, Accepted: 19 December 2021, Published online: 14 January 2022

\begin{abstract}
A zero-inertia micro-grid is a power system consisting of multiple renewable energy power sources and energy storage systems without the presence of conventional synchronous generators. In such a system, a large variation of the load or source sides during the islanded mode of operation extremely degrades the micro-grid's voltage and frequency stability. This study presents a virtual inertia-based predictive control strategy for a small-scale zero-inertia multiple distributed generators (DGs) micro-grid. In islanded mode, Voltage Model Predictive Control (VMPC) was implemented to control and maintain the voltage and frequency of the micro-grid. However, instabilities in frequency and voltage may rise at the Point of Common Coupling (PCC) due to large variations at both source and load sides. Therefore, the proposed virtual inertia loop calculates the amount of active power to be delivered or absorbed by each $D G$, and its effect is reflected in the estimated $d$ current component of the VMPC, thus providing better frequency regulation. In gridconnected mode, Direct Power Model Predictive Control (DPMPC) was implemented to manage the power flow between each DG and the utility grid. The control approach also enables the DG plug and play characteristics. The performance of the control strategy was investigated and verified using the PSCAD/EMTDC software platform.
\end{abstract}

\section{Keywords}

zero-inertia micro-grid, virtual inertia, Model Predictive Control (MPC), parallel DG system operation, power quality

\section{Introduction}

Due to rising environmental issues as well as the depletion of conventional sources such as coal, oil products, and Uranium, conventional power generation plants are being replaced by clean energy sources [1]. Wind and solar are the most used renewable energy sources to produce electricity. However, they are stochastic in nature and their integration into the utility grid needs special care at both hardware and software levels [2]. The concept of micro-grid facilitates the idea of renewable energy sources integration to the utility grid. It consists of several distributed generation (DG) units working together, and the total collected power is either integrated into the utility grid or fed to the loads directly [3]. Flexible microgrid operation requires sophisticated control topologies. In grid-connected mode, the voltage and frequency support is generally provided by the utility grid. Therefore, the output active and reactive powers of each DG within the micro-grid can be controlled. In contrast, the voltage, frequency, and power-sharing capability of each DG have to be managed during islanded mode operation either in a centralized or decentralized manner, so the control topology becomes more complex. Moreover, as a standalone system without the utility grid support and unlike synchronous generators, renewable energy sources such as PV and wind add no inertia to the Point of Common Coupling (PCC) since they are interfaced to the system through Voltage Source Inverters (VSIs). Thus, the inertia of the islanded mode micro-grid is very small and any large changes in the load or source can impose a great threat to the micro-grid's voltage and frequency stability.

Micro-grid control can be divided into three levels primary, secondary, and tertiary control [4]. The primary control consists of two control stages (i.e., the first and second stages). The first stage, which is called VSI output control, regulates the output active and reactive powers of each DG in grid-connected mode while it regulates the output voltage and frequency of each DG in islanded mode. However, the first stage control is not capable of 
stabilizing the voltage and frequency of the entire microgrid that consists of multiple DGs in islanded mode. Therefore, the second stage of the primary control ensures proper power-sharing among the DGs within the microgrid as well as stabilizes the micro-grid system's voltage and frequency. It can be categorized if the procedure is based on a) communication link or b) without communication link (i.e., droop-based) [5]. The methods that incorporate communication links include centralized control [6], distributed control [7], master-slave control [8], and angle droop control [9]. With several limitations such as the stochastic nature of the power source and constraint on the physical location of each DG unit, communication-less topologies are preferred over such topologies where the communication link is required. Several such methods without communication links include P-F/Q-U droop control [10], P-U/Q-F droop control [11], and virtual frame transformation-based methods [12].

Different control methods have been reported as the primary control, and the most simple and practical method is proportional integral and derivative (PID) control [13-15]. PID control is easy to design, tune, and implement. However, classical control suffers from performance degradation when the system is coupled such as micro-grid and it is also being subjected to disturbances. Such types of classical control methods have been reported in [16-20] for the primary loop control of multiple DG micro-grid. A virtual-flux-based control method without the requirement of the communication link is reported [21], where power-sharing is achieved using the flux amplitude and phase. All the reported methods in the above literature do not take into consideration the effect of virtual inertia and stability issues of a micro-grid with large variations at source and load sides. Several virtual inertia-based control methods have been reported for the islanded operation of a micro-grid that includes the frequency stability control of two-stage PV inverters based micro-grid [22], a virtual inertia scheme considering the communication delays of the link [23], a predictive controller based on virtual inertia concepts in [24], and a robust virtual inertia control method in [25].

Asapromising controlstrategy, Model Predictive Control (MPC) has been widely applied in applications that include VSIs, active front end rectifiers, neutral point-clamped multilevel converters, and matrix converters [26-28]. These works illustrate that by using MPC there is no need for tuning parameters as compared to conventional PI control. In addition, unlike the PI controller, MPC generates the switching signals internally without the need for any pulse width modulation (PWM) generators. The works also show that MPC is able to decouple variables and provide better responses compared to the PI control approach. Finally, multiple control objectives and constraints can be included in the control action at the same time which cannot be achieved by PI control. The main idea of MPC is the use of a system model to predict the future values of the controlled variables. A cost function is then used to determine the optimal future value by minimizing the error between the reference and predicted values. In [24] a virtual inertia-based control scheme is proposed however the virtual inertia is compensated locally.

Based on the above literature review, this paper proposes a centralized virtual inertia-based Model Predictive Control scheme for small-scale zero-inertia multiple DG micro-grid. The main contribution of this research work includes the following:

1. The grid-connected mode control is capable of managing the output power of each DG and enables flexible power regulation between the micro-grid and the utility grid.

2. Islanded mode control is capable of maintaining micro-grid voltage and frequency, and improving the micro-grid stability by the synthetic virtual inertia support. Also, providing a precise power-sharing scheme among DGs.

3. Adjustment of the power-sharing among the DGs at any time during islanded mode operation.

4. Plug and play DG operation.

The rest of the paper is organized as follows. Section 2 explains the system description, Section 3 describes the system modeling and control strategies, Section 4 discusses the results, and finally, the conclusion is made in Section 5 .

\section{System description}

The micro-grid system structure considered in this work for implementing the proposed MPC of both grid-connected and islanded modes of operation is shown in Fig. 1. The micro-grid consists of two feeders and energy storage systems. Each feeder represents a distributed generator system. The DG system is interfaced to the point of common coupling (PCC) via a three-phase two-level inverter with an LC filter. A resistor is connected in series with the capacitor filter to damp the transient oscillations of the filter [29]. A utility grid is connected to the point of common coupling through a static switch to disconnect 


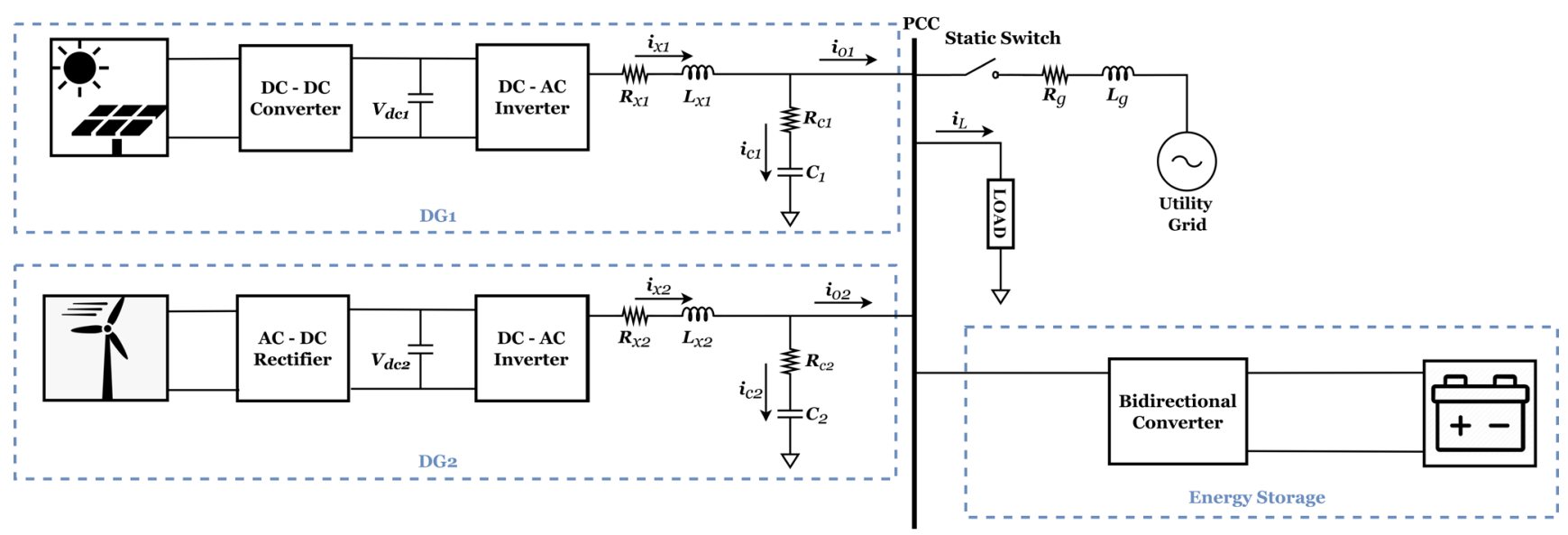

Fig. 1 Studied micro-grid system

the micro-grid in case of a stand-alone operation. A threephase RL electrical load is connected to the PCC to present a regular micro-grid load. The scope of this paper is to control the DC-AC inverters' output of DG1 and DG2. Therefore, the Direct Power Model Predictive Control (DPMPC) is implemented to control the active and reactive powers of each DG in grid-connected mode while Voltage Model Predictive Control (VMPC) with supported virtual inertia is implemented in islanded mode to maintain the voltage and frequency stability of the micro-grid. Knowing that the proposed control strategy can be implemented for micro-grids with more than two DGs. The system model, DPMPC, and VMPC design are discussed in Section 3.

\section{System models and controllers design}

The system model and controllers in this work are designed and implemented in $\alpha \beta$ frame. The component of $a b c$ frame is transferred to $\alpha \beta$ frame using Clarke's transformation

$$
\left[\begin{array}{l}
u_{\alpha} \\
u_{\beta}
\end{array}\right]=\frac{2}{3}\left[\begin{array}{ccc}
1 & \frac{-1}{2} & \frac{-1}{2} \\
0 & \frac{\sqrt{3}}{2} & -\frac{\sqrt{3}}{2}
\end{array}\right]\left[\begin{array}{l}
u_{a} \\
u_{b} \\
u_{c}
\end{array}\right]
$$

whereby a three-phase component

$$
\begin{aligned}
& u_{a}=U \cos (w t) \\
& u_{b}=U \cos \left(w t-\frac{2 \pi}{3}\right) \\
& u_{c}=U \cos \left(w t+\frac{2 \pi}{3}\right)
\end{aligned}
$$

is transferred to $\alpha \beta$ as

$$
\begin{aligned}
& u_{\alpha}=U \cos (w t) \\
& u_{\beta}=U \sin (w t) .
\end{aligned}
$$

\subsection{Active and reactive power control in grid-connected mode}

The micro-grid operates in grid-connected mode when the static switch Fig. 1 is closed. Since the utility grid is stiff, the micro-grid voltage and frequency are enforced by the utility grid. Therefore, the output active and reactive power of a DG can be controlled. DPMPC is implemented to enable flexible power regulation between the micro-grid and utility grid. Fig. 2 shows the diagram of the DPMPC implemented in the grid-connected mode of the microgrid operation. The system model of Fig. 1, in this case, is derived as [30]

$i_{x i}=i_{c i}+i_{o i}$

$v_{x i}=v_{P C C}+L_{x i} \frac{d i_{x i}}{d t}+i_{x i} R_{x i}$,

where the notation $i$ represents the components of $\mathrm{DG}_{i}$. The $i_{x}$ is the output current of the inverter, $i_{c}$ is the capacitor current, and $i_{o}$ is the output current of the DG system flow to the PCC. The $v_{\text {PCC }}$ is the voltage at the point of common coupling. The $v_{x}$ is the output voltage of the three-phase two-level inverter. Using MPC, the value of $v_{x}$ is determined by the means of Space Cector Modulation (SVM) which is shown in Table 1. The three-phase twolevel inverter consists of six switches with two switches in each leg. The gating signals of the upper switches are controlled by $S_{1}, S_{2}$, and $S_{3}$ while the lower switches are controlled inversely. 


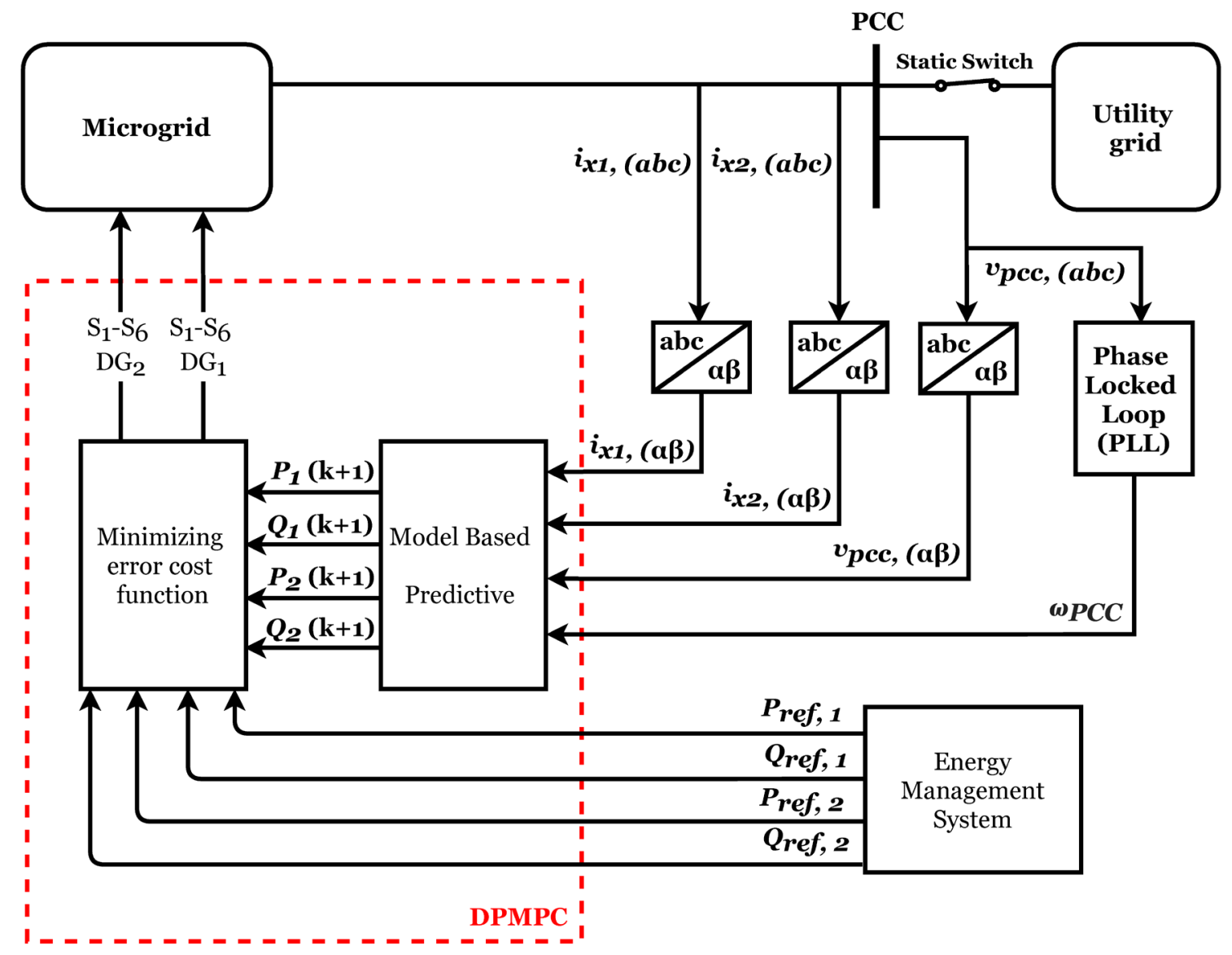

Fig. 2 DPMPC in grid-connected

Table 1 Space vector modulation of three-phase two-level inverter

\begin{tabular}{lcccc}
\hline Mode & $S_{1}$ & $S_{2}$ & $S_{3}$ & $v_{x}$ \\
\hline 0 & 0 & 0 & 0 & 0 \\
1 & 0 & 0 & 1 & $\frac{2}{3} V_{d c} \angle 0$ \\
2 & 0 & 1 & 1 & $\frac{2}{3} V_{d c} \angle 60$ \\
3 & 0 & 1 & 0 & $\frac{2}{3} V_{d c} \angle 120$ \\
4 & 1 & 1 & 0 & $\frac{2}{3} V_{d c} \angle 180$ \\
5 & 1 & 0 & 0 & $\frac{2}{3} V_{d c} \angle 240$ \\
6 & 1 & 0 & 1 & $\frac{2}{3} V_{d c} \angle 300$ \\
7 & 1 & 1 & 1 & 0 \\
\hline
\end{tabular}

The active and reactive power exchange between $\mathrm{DG}_{i}$ and utility grid is obtained as

$$
\left[\begin{array}{c}
P_{i} \\
Q_{i}
\end{array}\right]=\frac{3}{2}\left[\begin{array}{ll}
v_{P C C_{\alpha}} & v_{P C C_{\beta}} \\
v_{P C C_{\beta}} & -v_{P C C_{\alpha}}
\end{array}\right]\left[\begin{array}{l}
i_{x i_{\alpha}} \\
i_{x i_{\beta}}
\end{array}\right] .
$$

The derivatives of active and reactive power with respect to time $t$ are obtained from Eq. (9) as

$$
\begin{aligned}
& \frac{d P_{i}}{d t}=\frac{3}{2}\left(\begin{array}{l}
\frac{d v_{\mathrm{PCC}, \alpha}}{d t} i_{x i, \alpha}+v_{\mathrm{PCC}, \alpha} \frac{d i_{x i, \alpha}}{d t}+\frac{d v_{\mathrm{PCC}, \beta}}{d t} i_{x i, \beta} \\
+v_{\mathrm{PCC}, \beta} \frac{d i_{x i, \beta}}{d t}
\end{array}\right) \\
& \frac{d Q_{i}}{d t}=\frac{3}{2}\left(\begin{array}{l}
\frac{d v_{\mathrm{PCC}, \beta}}{d t} i_{x i, \alpha}+v_{\mathrm{PCC}, \beta} \frac{d i_{x i, \alpha}}{d t}-\frac{d v_{\mathrm{PCC}, \alpha}}{d t} i_{x i, \beta} \\
-v_{\mathrm{PCC}, \alpha} \frac{d i_{x i, \beta}}{d t}
\end{array}\right)
\end{aligned}
$$

and considering a balanced sinusoidal line voltage [31]

$$
\frac{d v_{\mathrm{PCC}, \alpha}}{d t}=-\omega v_{\mathrm{PCC}, \beta}
$$

$$
\frac{d v_{\mathrm{PCC}, \beta}}{d t}=\omega v_{\mathrm{PCC}, \alpha},
$$

where $\omega$ is the angular frequency of the voltage at the PCC. Substituting Eq. (12), Eq. (13), and Eq. (8) into Eq. (10) and Eq. (11) yield 


$$
\begin{aligned}
& \frac{d P_{i}}{d t}=-\frac{R_{x i}}{L_{x i}} P_{i}-\omega Q_{i}+\frac{3}{2 L_{x i}}\left(v_{\mathrm{PCC}, \alpha} v_{x i, \alpha}+v_{\mathrm{PCC}, \beta} v_{x i, \beta}\right) \\
& -\frac{3}{2 L_{x i}}\left(v_{\mathrm{PCC}, \alpha}^{2}+v_{\mathrm{PCC}, \beta}^{2}\right) \\
& \frac{d Q_{i}}{d t}=\omega P_{i}-\frac{R_{x i}}{L_{x i}} Q_{i}+\frac{3}{2 L_{x i}}\left(v_{\mathrm{PCC}, \beta} v_{x i, \alpha}-v_{\mathrm{PCC}, \alpha} v_{x i, \beta}\right) .
\end{aligned}
$$

The discrete-time of a differential equation can be obtained using the Euler forward method to approximate the derivative [32]

$$
\frac{d u}{d t} \simeq \frac{u(k+1)-u(k)}{T_{s}},
$$

where $u(k)$ and $u(k+1)$ are the present and predicted future values of the component $u$, respectively. $T_{s}$ is the sampling time. The discrete-time of $P_{i}$ and $Q_{i}$ are obtained by applying Eq. (16) into Eq. (14) and Eq. (15)

$$
\begin{aligned}
& P_{i}(k+1)=P_{i}(k) \\
& +T_{s}\left[\begin{array}{l}
\frac{-R_{x i}}{L_{x i}} P_{i}(k)-\omega Q_{i}(k) \\
+\frac{3}{2 L_{x i}}\left(v_{\mathrm{PCC}, \alpha}(k) v_{x i, \alpha}(k)+v_{\mathrm{PCC}, \beta}(k) v_{x i, \beta}(k)\right) \\
-\frac{3}{2 L_{x i}}\left(v_{\mathrm{PCC}, \alpha}^{2}(k)+v_{\mathrm{PCC}, \beta}^{2}(k)\right)
\end{array}\right. \\
& Q_{i}(k+1)=Q_{i}(k) \\
& +T_{s}\left[\begin{array}{l}
\frac{-R_{x i}}{L_{x i}} Q_{i}(k)+\omega P_{i}(k) \\
+\frac{3}{2 L_{x i}}\left(v_{\mathrm{PCC}, \beta}(k) v_{x i, \alpha}(k)-v_{\mathrm{PCC}, \alpha}(k) v_{x i, \beta}(k)\right)
\end{array}\right] .
\end{aligned}
$$

In each sampling time, DPMPC predicts eight values of $P_{i}(k+1)$ and $Q_{i}(k+1)$ by evaluating each voltage vector Table 1 of $v_{x}$ in Eq. (17) and Eq. (18). In order to determine the optimal voltage vector that produces the least error between the reference and predicted values, a cost function Eq. (19) is used. The reference active and reactive powers values are generated by an Energy Management System (EMS) and fed to the DPMPC controller Fig. 2. Once the optimal voltage vector is determined for each DG, switching signals $\left(S_{1}-S_{6}\right)$ are generated by the controllers and sent to the DGs. The control process steps are shown in Fig. 3.

$$
J=\sum_{i=1}^{n}\left[\begin{array}{l}
\left(P_{r e f, i}(k+1)-P_{i}(k+1)\right)^{2} \\
+\left(Q_{r e f, i}(k+1)-Q_{i}(k+1)\right)^{2}
\end{array}\right]
$$

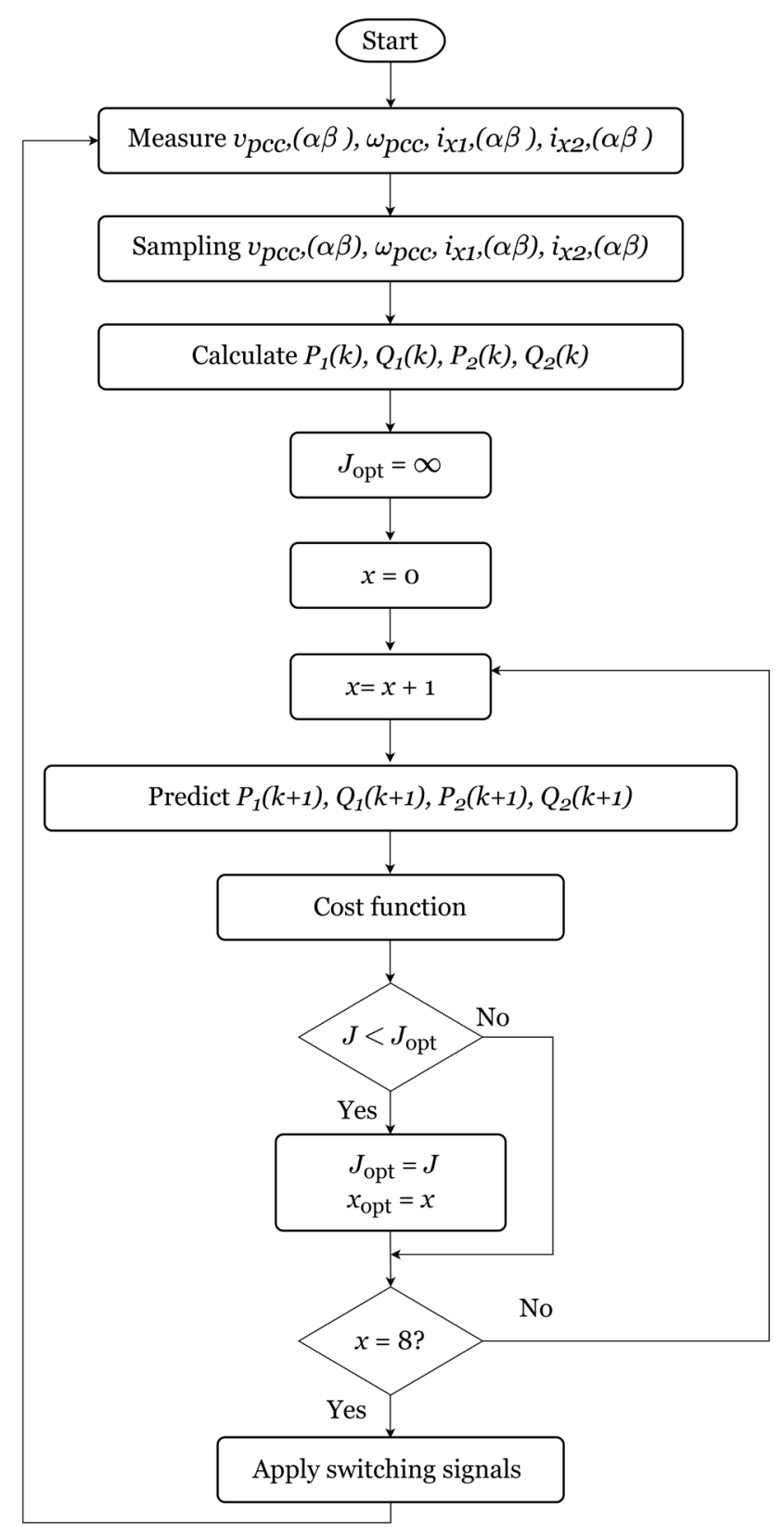

Fig. 3 DPMPC flowchart

\subsection{Voltage and frequency control and power-sharing in islanded mode}

When the static switch Fig. 1 is open, the micro-grid operates as a stand-alone system. Unlike the grid-connected mode, voltage and frequency must be maintained in islanded mode to ensure the stability of the microgrid operation system. VMPC in Fig. 4 is used to control the voltage and frequency of the micro-grid and enable a proper power-sharing between the DGs in the micro-grid. The system model in the islanded mode is obtained as [33] 


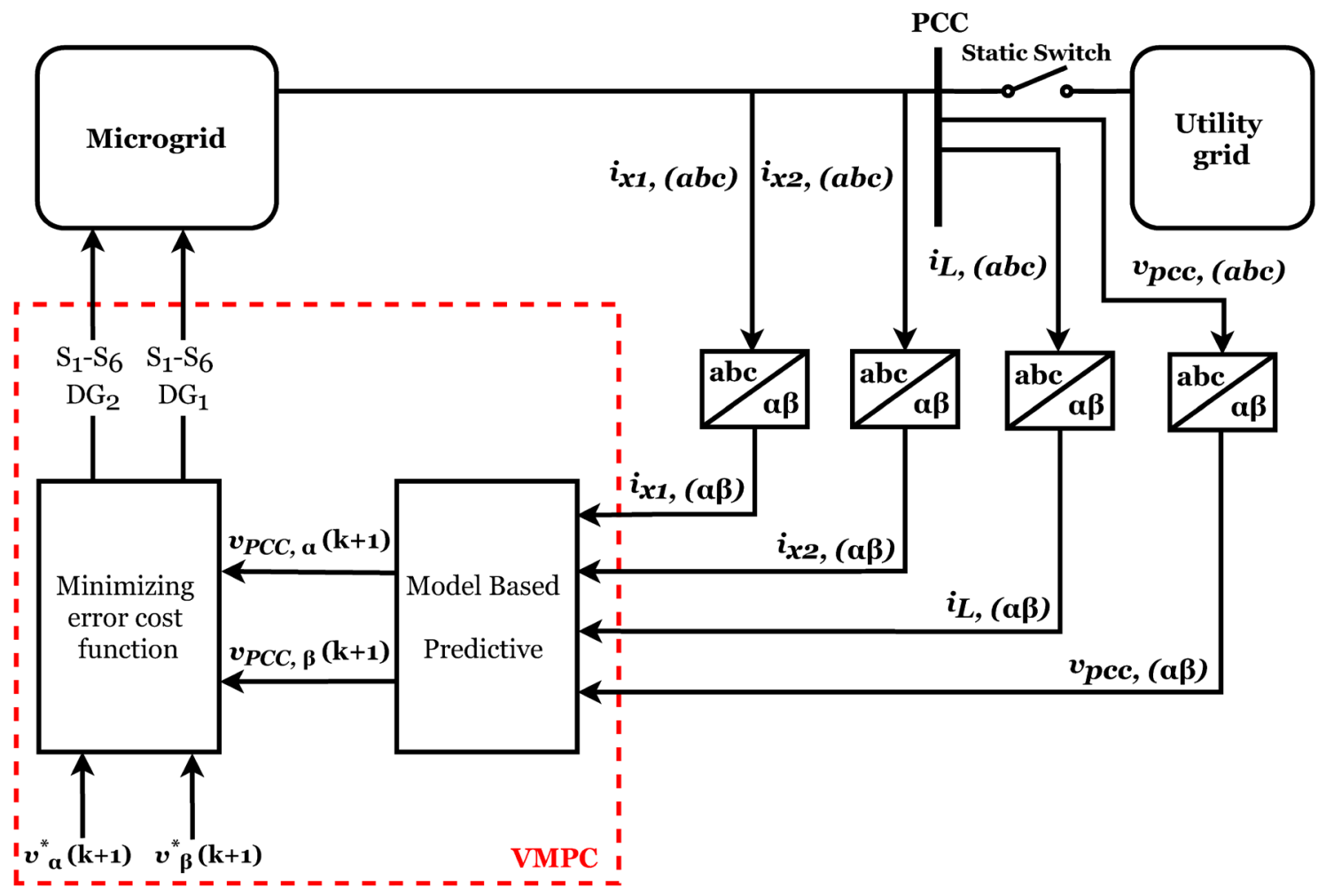

Fig. 4 VMPC in islanded mode

$v_{x i}=v_{\mathrm{PCC}}+L_{x i} \frac{d i_{x i}}{d t}+i_{x i} R_{x i}$

$i_{L}=\left(i_{x 1}-C_{1} \frac{d v_{\mathrm{PCC}}}{d t}\right)+\left(i_{x 2}-C_{2} \frac{d v_{\mathrm{PCC}}}{d t}\right)$,

where $i_{L}$ is the load current. Equations (20) and (21) can be rearranged as

$\frac{d i_{x i}}{d t}=\frac{1}{L_{x i}}\left(v_{x i}-v_{\mathrm{PCC}}-i_{x i} R_{x i}\right)$

$\frac{d v_{\mathrm{PCC}}}{d t}=\frac{1}{C_{1}+C_{2}}\left(i_{x 1}+i_{x 2}-i_{L}\right)$

Using Eq. (16), the discrete-time equations of Eqs. (22) and (23) are obtained as

$i_{x i}(k+1)=i_{x i}(k)+\frac{T_{S}}{L_{x i}}\left(v_{x i}(k)-v_{\mathrm{PCC}}(k)-i_{x i}(k) R_{x i}\right)$

$v_{\mathrm{PCC}}(k+1)=v_{\mathrm{PCC}}(k)$

$+\frac{T_{S}}{C_{1}+C_{2}}\left(i_{x 1}(k+1)+i_{x 2}(k+1)-i_{L}(k)\right)$.

The cost function Eq. (26) has two control objectives. The first objective, which is the first term, is voltage tracking. The second objective is to enable appropriate power-sharing among the DGs [33]. Similar to DPMPC, VMPC predicts eight values of $v_{\mathrm{PCC}}(k+1)$. Therefore, the cost function is used to determine the optimal value of $v_{x}$ which results in the lowest error between the reference and predicted voltage values. Moreover, the cost function regulates the output power of each DG by adjusting the ratio values $\zeta_{1}$ and $\zeta_{2}$ of $\mathrm{DG}_{1}$ and $\mathrm{DG}_{2}$ output currents. Note that the multiplication of $\zeta_{1}$ and $\zeta_{2}$ must equal unity. Since the power-sharing term is considered as constraints in the cost function, weighting factors $W_{v}$ and $W_{i}$ are used [34].

$$
\begin{aligned}
& J_{v}=W_{v}\left[v^{*}(k+1)-v_{\mathrm{PCC}}(k+1)\right]^{2} \\
& +W_{i}\left[\left(i_{x 1}(k+1)-\zeta_{1} i_{x 2}(k+1)\right)^{2}+\left(i_{x 2}(k+1)-\zeta_{2} i_{x 1}(k+1)\right)^{2}\right]
\end{aligned}
$$

\subsection{Virtual inertia loop implementation}

The control technique VMPC presented in the previous section is capable of maintaining the micro-grid's voltage and frequency in islanded mode during normal operation as well as in the cases of small changes in the load or source side. However, in situations where there is a large change in the load or source side, the micro-grid's voltage and frequency may not be stable due to the inertia absence especially in the zero-inertia micro-grid which does not include the conventional synchronous generators. 
Therefore, to enhance the VMPC performance and maintain the micro-grid stability during islanded mode operation, a synthetic inertial loop is included in the controller. Fig. 5 shows the integration of the virtual inertia control loop to the VMPC. As it is known that using the $d-q$ reference frame, the active power specifically depends on the current $d$ component. Therefore, since VMPC is implemented in the $\alpha \beta$ frame in this work, the estimated currents of Eq. (24) are transformed to the $d-q$ reference frame, and then the inertial component of the current is calculated from the inertia loop is added to the $d$ component of the estimated currents. Finally, the $d-q$ currents are transformed to $\alpha \beta$ frames, and they are used for predicting the voltage at PCC Eq. (25). For testing purposes, both DGs contribute equal active power for enhancing the virtual inertia of the PCC. Fig. 6 shows the VMPC algorithm flowchart including the synthetic inertial loop.

\section{Simulation results and performance evaluation}

The proposed micro-grid of Fig. 1 was simulated using PSCAD/EMTDC. DPMPC and VMPC controllers were coded using FORTRAN and implemented in PSCAD with a sampling frequency of $25 \mathrm{kHz}$. Since the MPC switching frequency is variable, the maximum average switching frequencies of both DPMPC and VMPC were set to $4 \mathrm{kHz}$ and $4.5 \mathrm{kHz}$, respectively. The parameters of the studied micro-grid system are shown in Table 2. Several case studies are carried out to investigate the performance of the proposed control strategies. The control parameters of the virtual inertia loop are chosen as follows: $K_{p}=0.005$ and $K_{i}=0.07$.

\subsection{Active and reactive power regulation in grid- connected mode}

This case study examines the robustness of the proposed DPMPC controller to allow flexible power regulation in grid-connected mode. Both active and reactive power components of each DG can be regulated, so any change in the load will be compensated by the utility grid unless the power reference points are changed. Fig. 7 shows the instantaneous and reference active and reactive powers values where they are represented as solid and dashed lines, respectively.

To examine the proposed controller a step change of $4 \mathrm{~kW}$ was applied to $\mathrm{DG}_{1}$ 's active power $\left(\mathrm{PDG}_{1}\right)$ at $t=0.2 \mathrm{~s}$, it can be seen from Fig. 7 that the active power is controlled independently by following its new reference level in less than $0.1 \mathrm{~s}$. Moreover, to verify the robustness of the controller, the reactive power of $\mathrm{DG}_{2}$ is reset from $2 \mathrm{kVar}$ to $9 \mathrm{kVar}$ at $t=0.5 \mathrm{~s}$. As shown in Fig. $7, \mathrm{QDG}_{2}$ set point is achieved at $t=0.6 \mathrm{~s}$. It is clear from the presented results in Fig. 7 that the controller is robust to decouple both active and reactive power smoothly during grid-connected micro-grid operation.

\subsection{Voltage and frequency regulation in islanded mode}

In this case study, the system was reconfigured to verify the proposed VMPC system capability in regulating the system voltage and frequency by controlling the output voltage and frequency of each DG in islanded mode. Moreover, both active and reactive powers were decoupled as required by the load. Despite grid-connected mode, in islanded mode, DGs must respond to support the system

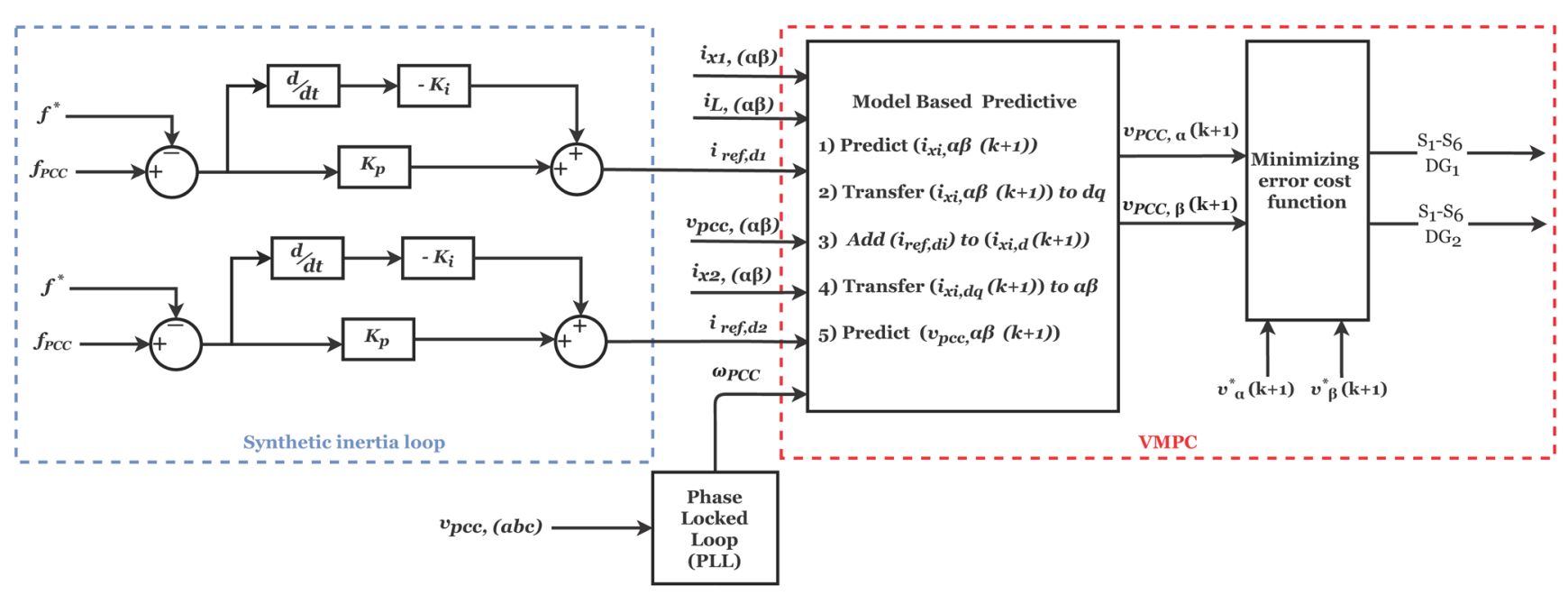

Fig. 5 Synthetic inertia loop 


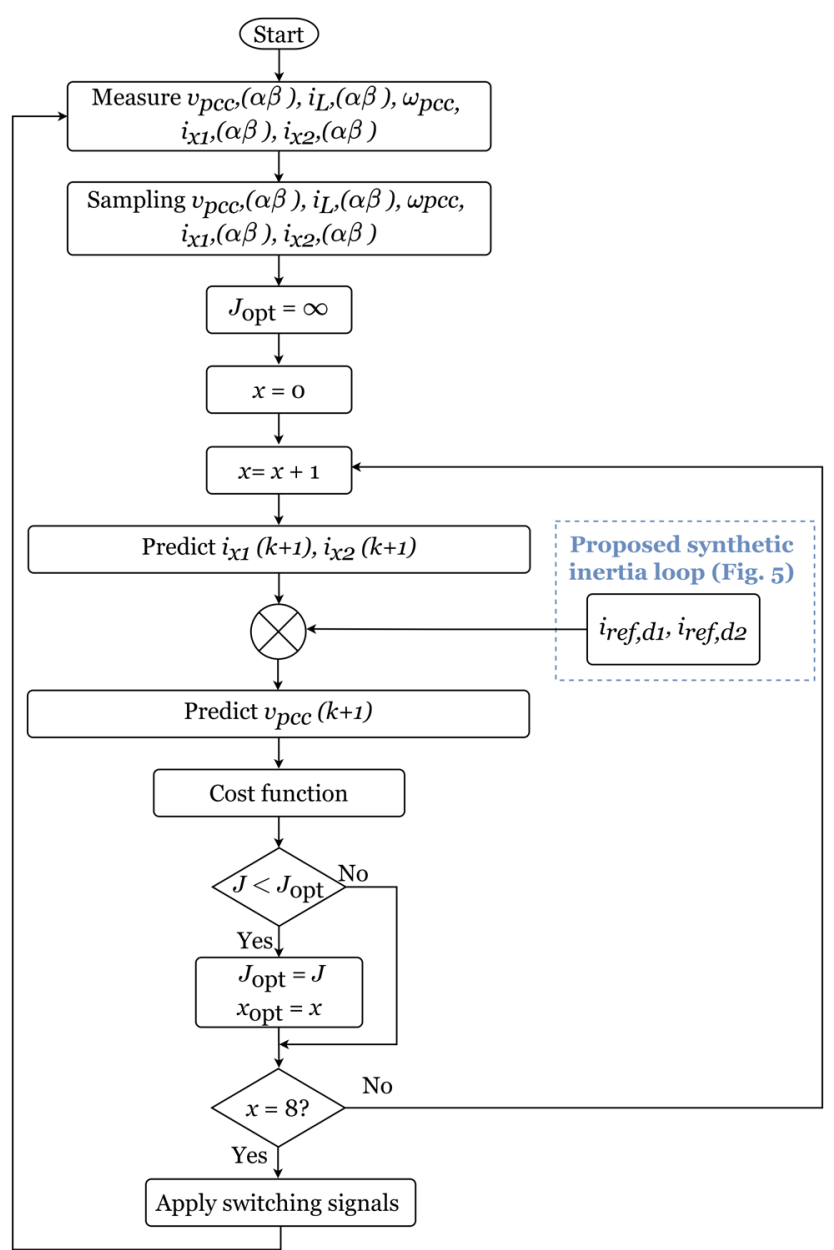

Fig. 6 VMPC flowchart with synthetic inertia loop

Table 2 Studied micro-grid system parameters

\begin{tabular}{lcc}
\hline Parameter & Symbol & Value \\
\hline DC-link Voltage & $V_{d c 1}, V_{d c 2}$ & $1 \mathrm{kV}$ \\
DG 1 Power Rating & $S_{\mathrm{DG} 1}$ & $50 \mathrm{kVA}$ \\
DG $_{2}$ Power Rating & $S_{\mathrm{DG} 2}$ & $40 \mathrm{kVA}$ \\
Rated Frequency & $f_{\text {rated }}$ & $60 \mathrm{~Hz}$ \\
Filter Inductance & $L_{x 1}, L_{x 2}$ & $3 \mathrm{mH}$ \\
ESR of $L_{x}$ & $R_{x 1}, R_{x 2}$ & $0.02 \Omega$ \\
Filter Capacitor & $C_{1}, C_{2}$ & $20 \mu \mathrm{F}$ \\
Damping Resistance & $R_{c 1}, R_{c 2}$ & $0.8 \Omega$ \\
Utility Grid Voltage & $V_{g}$ & $380 \mathrm{~V}_{\mathrm{LL}, \mathrm{RMS}}$ \\
Grid Parameters & $R_{g}, L_{g}$ & $0.002 \Omega, 15 \mu \mathrm{H}$ \\
\hline
\end{tabular}

requirements during any load changing. Fig. 8 shows the system response including the delivered active and reactive power of both DGs in the islanded mode. It can be seen in Fig. 8 that more load of $32 \mathrm{~kW}$ and 15 kVar is connected to the system at $t=0.3 \mathrm{~s}$. Each DG response to the load increase by delivering ( $16 \mathrm{~kW}$ and $7.5 \mathrm{kVar}$ ) the required active and reactive power. Furthermore, the load decreases at $t=0.6 \mathrm{~s}$, and it can be seen that each

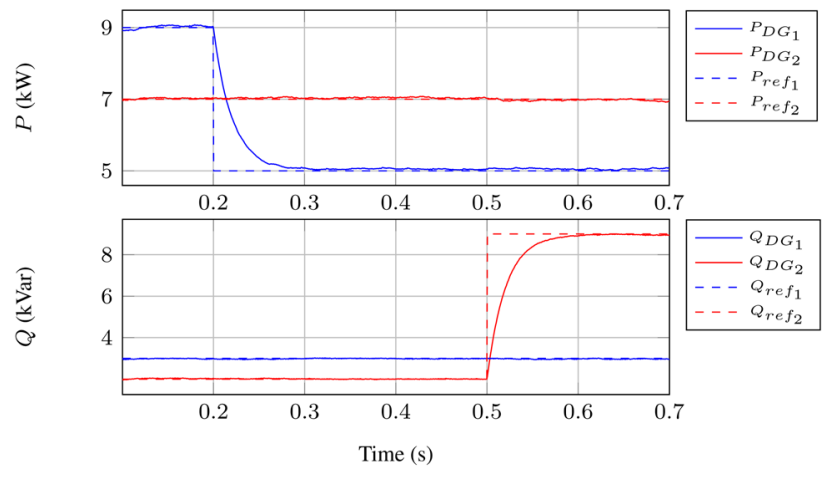

Fig. 7 Active and reactive powers of the two DGs during grid-connected mode
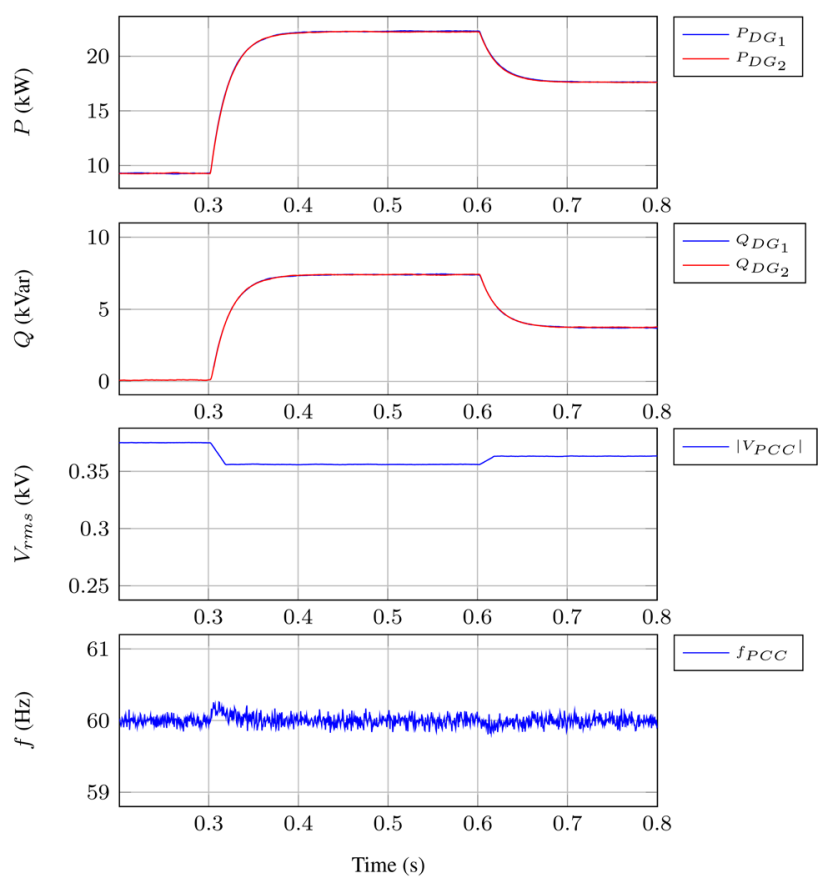

Fig. 8 System response to load change in islanded mode

DG adjusted its output by reducing the output active and reactive powers to be matched with the new load value. The results show the efficient response of the control system to compensate for both active and reactive power and maintain the system frequency and voltage within the safety margin.

\subsection{Plug-and-play operation}

Plug-and-play operation is applied in this scenario to show the capability of the control system, as shown in Fig. 9 $\mathrm{DG}_{2}$ is isolated at $t=0.5 \mathrm{~s}, \mathrm{DG}_{1}$ compensates the system during the outage of $\mathrm{DG}_{2}$. After $0.4 \mathrm{~s} \mathrm{DG}_{2}$ is reconnected to the service without any disturbances to the system. The voltage and frequency of the system remain at the same level without any deviation during these disturbances as can be seen in Fig. 9 . 

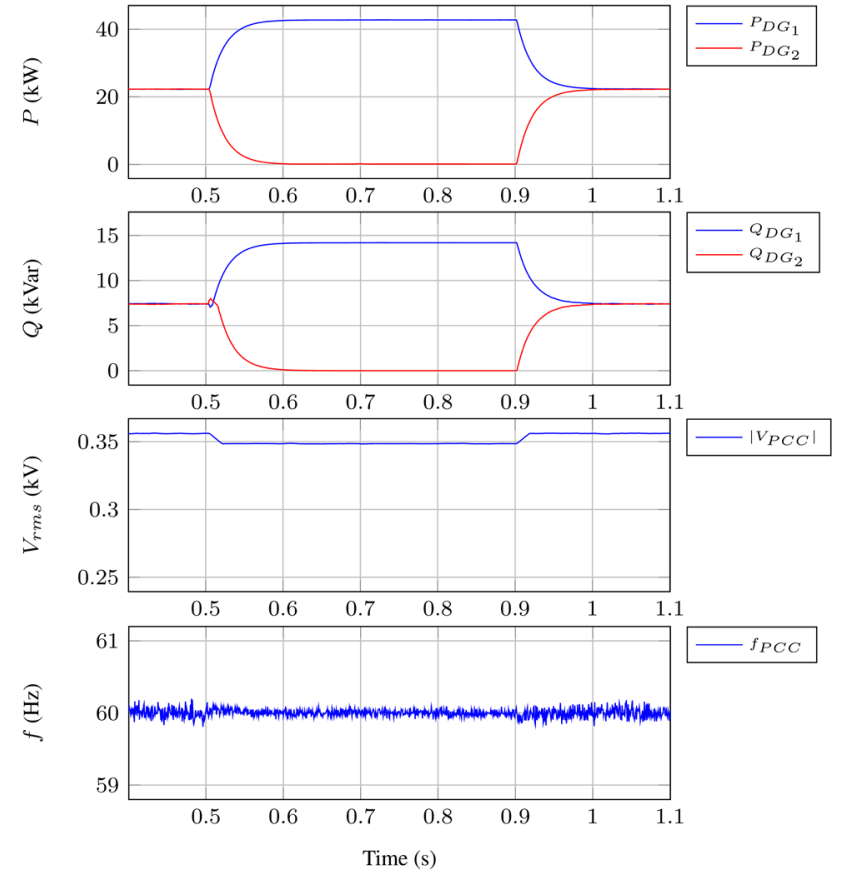

Fig. 9 Plug-and-play of DGs operation in islanded mode

\subsection{Power-sharing among DGs in islanded mode}

This case study is carried out to present the capability of the proposed method to enable precise power-sharing among the DGs in the islanded mode. It can be seen in Fig. 10, in the beginning, the ratio factors of $\zeta_{1}$ and $\zeta_{2}$ are set to $(1: 1)$. Then the ratio factors are changed to $(2: 0.5)$ at $t=0.4 \mathrm{~s}$. After that at $t=0.6 \mathrm{~s}$, the ratio factors are reset again to $(0.25: 4)$. The presented results show that each DG
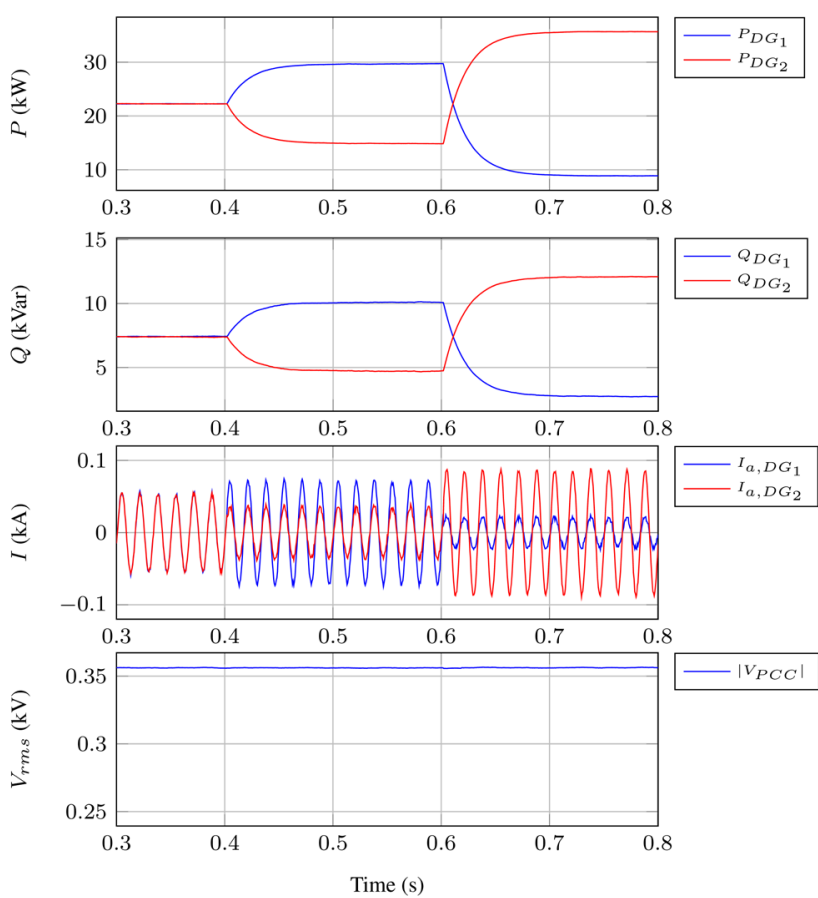

Fig. 10 System response to current ratios changes in islanded mode adjusts its output active and reactive power to meet the new set of the current ratio, and maintain the system voltage and frequency without any fluctuations.

\subsection{Virtual inertia contribution by DGs}

This case study verifies the capability of the proposed control method for the addition of virtual inertia to the PCC, thus enhancing the frequency stability of the micro-grid in the islanded mode of operation. Figs. 11 and 12 show the PCC frequency stability with and without the inertia loop. It is obvious from Fig. 11, that the PCC frequency nadir reaches $55 \mathrm{~Hz}$ when the load active power is changed from approximately $8 \mathrm{~kW}$ to $19 \mathrm{~kW}$ without virtual inertia support, while it is limited to $58.8 \mathrm{~Hz}$ with virtual inertia support. The corresponding reference $i_{d}$ virtual inertia current component by virtual inertia loop controller is also shown
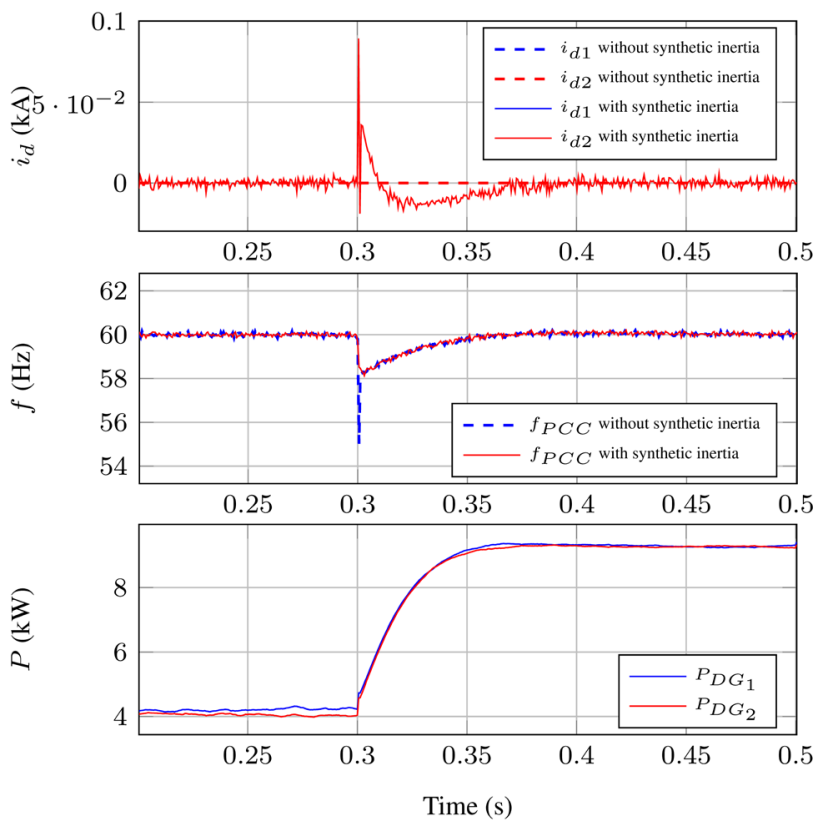

Fig. 11 System response to large load step change in islanded mode
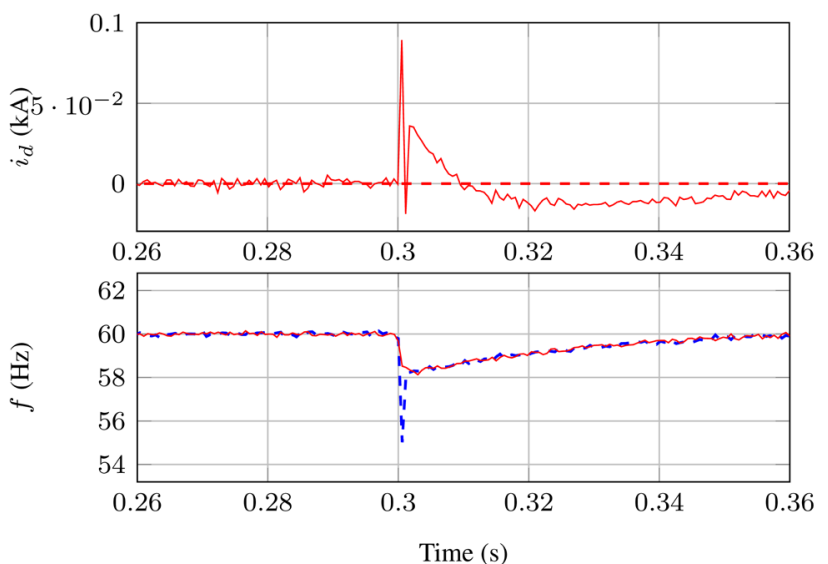

Fig. 12 Zoom version of Fig. 11 
in Fig. 11. Approximately $90 \mathrm{~A}$ of the current is contributed by both the DGs in response to the active power variation caused by sudden load changes. The zoom version of Fig. 11 is shown in Fig. 12 for further clarification.

\section{Conclusion}

In this article, a virtual inertia supported model predictive controller is proposed for the stability enhancement of multiple DG small-scale zero-inertia micro-grids. In grid-connected mode, DPMPC was implemented to control both active and reactive powers of each DG while VMPC was used to control the output voltage of each DG as well as stabilize the micro-grid's voltage and frequency. A synthetic inertial loop was included in the VMPC to improve the micro-grid stability during

\section{References}

[1] Kateeb, I. A., Bikdash, M., Chopade, P. "Back to the future Renewable Energy Sources and green Smart Grid", In: Proceedings of IEEE Southeastcon, Nashville, TN, USA, pp. 147-152, 2011. https://doi.org/10.1109/SECON.2011.5752923

[2] Yu, F. R., Zhang, P., Xiao, W., Choudhury, P. "Communication systems for grid integration of renewable energy resources", IEEE Network, 25(5), pp. 22-29, 2011. https://oi.org/10.1109/MNET.2011.6033032

[3] Stadler, M., Naslé, A. "Planning and implementation of bankable microgrids", The Electricity Journal, 32(5), pp. 24-29, 2019. https://doi.org/10.1016/j.tej.2019.05.004

[4] Olivares, D., E., Mehrizi-Sani, A., Etemadi, A. H., Cañizares, C. A., Iravani, R., Kazerani, M., Hajimiragha, A. H., Gomis-Bellmunt, O., Saeedifard, M., Palma-Behnke, R., Jiménez-Estévez, G. A., Hatziargyriou, N. D. "Trends in Microgrid Control", IEEE Transactions on Smart Grid, 5(4), pp. 1905-1919, 2014. https://doi.org/10.1109/TSG.2013.2295514

[5] Palizban, O., Kauhaniemi, K. "Hierarchical control structure in microgrids with distributed generation: Island and grid-connected mode", Renewable and Sustainable Energy Reviews, 44, pp. 797-813, 2015. https://doi.org/10.1016/j.rser.2015.01.008

[6] Singh, P., Paliwal, P., Arya, A. "A Review on Challenges and Techniques for Secondary Control of Microgrid", In: IOP Conference Series: Materials Science and Engineering, 561, Article No.: 012075, 2019.

https://doi.org/10.1088/1757-899X/561/1/012075

[7] Unamuno, E., Barrena, J. A. "Hybrid ac/dc microgrids-Part II: Review and classification of control strategies", Renewable and Sustainable Energy Reviews, 52, pp. 1123-1134, 2015. https://doi.org/10.1016/j.rser.2015.07.186

[8] Caldognetto, T., Tenti, P. "Microgrids Operation Based on MasterSlave Cooperative Control", IEEE Journal of Emerging and Selected Topics in Power Electronics, 2(4), pp. 1081-1088, 2014. https://doi.org/10.1109/JESTPE.2014.2345052 islanded mode operation. From the presented results, it is evident that the proposed strategy enables flexible active and reactive power regulation of each DG in grid-connected mode. In addition, it is also able to decouple both active and reactive power components during grid-connected micro-grid operation. Moreover, the proposed control is capable of maintaining the micro-grid's voltage and frequency and provides proper power-sharing among the DGs in islanded mode operation. The proposed controller also enables adjusting the output active and reactive power amounts of each DG at any time during the islanded mode of operation. It is shown that by adding the virtual inertia control loop to the controller in islanded mode, the micro-grid stability is enhanced. Finally, the smooth plug and play property is also verified.

[9] Majumder, R., Chaudhuri, B., Ghosh, A., Majumder, R., Ledwich, G., Zare, F. "Improvement of Stability and Load Sharing in an Autonomous Microgrid Using Supplementary Droop Control Loop", IEEE Transactions on Power Systems, 25(2), pp. 796-808, 2010. https://doi.org/10.1109/TPWRS.2009.2032049

[10] He, J., Li, Y. W. "An Enhanced Microgrid Load Demand Sharing Strategy", IEEE Transactions on Power Electronics, 27(9), pp. 3984-3995, 2012.

https://doi.org/10.1109/TPEL.2012.2190099

[11] Araújo, L. S., Narváez, D. I., Siqueira, T. G., Villalva, M. G. "Study and Development of a Modified Droop Control Strategy for Autonomous Microgrids", In: Proceedings of the World Congress on Engineering and Computer Science 2016 (WCECS), vol. 1, San Francisco, CA, USA, 2016, pp. 292-297.

[12] Li, Y., Li, Y. W. "Power Management of Inverter Interfaced Autonomous Microgrid Based on Virtual Frequency-Voltage Frame", IEEE Transactions on Smart Grid, 2(1), pp. 30-40, 2011. https://doi.org/10.1109/TSG.2010.2095046

[13] Tchuisseu, E. B. T., Gomila, D., Brunner, D., Colet, P. "Effects of dynamic-demand-control appliances on the power grid frequency", Physical Review E, 96(2), Article No.: 022302, 2017. https://doi.org/10.1103/PhysRevE.96.022302

[14] Soodi, H. A., Vural, A. M. "Single Phase Nine-Level Convertor Based STATCOM for Reactive Power Compensation and Power Factor Correlation", In: International Conference on Engineering Technology and their Applications (IICETA), Al-Najaf, Iraq, 2018, pp. 19-24. https://doi.org/10.1109/IICETA.2018.8458086

[15] Xu, Y., Li, F. "Adaptive PI Control of STATCOM for Voltage Regulation", IEEE Transactions on Power Delivery, 29(3), pp. 1002-1011, 2014.

https://doi.org/10.1109/TPWRD.2013.2291576 
[16] Milani, A. A., Cisneros, R., Chakrabortty, A., Husain, I. "A PassivityBased Globally Stabilizing PI Controller for Primary Control of Radial Power Distribution Systems", In: American Control Conference (ACC), Philadelphia, PA, USA, 2019, pp. 1295-1300. https://doi.org/10.23919/ACC.2019.8814934

[17] Jaafar, A., Alawieh, A., Ortega, R., Godoy, E., Lefranc, P. "PI Stabilization of Power Converters With Partial State Measurements", IEEE Transactions on Control Systems Technology, 21(2), pp. 560-568, 2013. https://doi.org/10.1109/TCST.2012.2186368

[18] Yao, W., Chen, M., Matas, J., Guerrero, J. M., Qian, Z. M. "Design and Analysis of the Droop Control Method for Parallel Inverters Considering the Impact of the Complex Impedance on the Power Sharing", IEEE Transactions on Industrial Electronics, 58(2), pp. 576-588, 2011. https://doi.org/10.1109/TIE.2010.2046001

[19] Nachiappan, A., Sundararajan, K., Malarselvam, V. "Current controlled voltage source inverter using Hysteresis controller and PI controller", In: International Conference on Power, Signals, Controls and Computation, Thrissur, India, 2012, pp. 1-6. https://doi.org/10.1109/EPSCICON.2012.6175247

[20] Lee, C. T., Chu, C. C., Cheng, P. T. "A New Droop Control Method for the Autonomous Operation of Distributed Energy Resource Interface Converters", IEEE Transactions on Power Electronics, 28(4), pp. 1980-1993, 2013. https://doi.org/10.1109/TPEL.2012.2205944

[21] Hu, J., Zhu, J., Dorrell, D. G., Guerrero, J. M. "Virtual Flux Droop Method-A New Control Strategy of Inverters in Microgrids", IEEE Transactions on Power Electronics, 29(9), pp. 4704-4711, 2014. https://doi.org/10.1109/TPEL.2013.2286159

[22] Huang, X., Wang, K., Li, G. "Virtual Inertia Based Control of Twostage Photovoltaic Inverters for Frequency Regulation in Islanded Micro-grid", In: IEEE Power \& Energy Society General Meeting (PESGM), Portland, OR, USA, 2018, pp. 1-5. https://doi.org/10.1109/PESGM.2018.8586544

[23] Alizadeh, G. A., Rahimi, T., Babayi Nozadian, M.H., Padmanaban, S., Leonowicz, Z. "Improving Microgrid Frequency Regulation Based on the Virtual Inertia Concept while Considering Communication System Delay", Energies, 12(10), Article No.: 2016, 2019. https://doi.org/10.3390/en12102016

[24] Kerdphol, T., Rahman, F. S., Mitani, Y., Hongesombut, K., Küfeoğlu, S. "Virtual Inertia Control-Based Model Predictive Control for Microgrid Frequency Stabilization Considering High Renewable Energy Integration", Sustainability, 9(5), Article No.: 773,2017 https://doi.org/10.3390/su9050773

[25] Kerdphol, T., Rahman, F. S., Mitani, Y., Watanabe, M., Küfeoğlu, S. K. "Robust Virtual Inertia Control of an Islanded Microgrid Considering High Penetration of Renewable Energy", IEEE Access, 6, pp. 625-636, 2018. https://doi.org/10.1109/ACCESS.2017.2773486
[26] Rodriguez, J., Pontt, J., Silva, C., Cortes, P., Amman, U., Rees, S. "Predictive current control of a voltage source inverter", In: IEEE 35th Annual Power Electronics Specialists Conference (IEEE Cat. No.04CH37551), Aachen, Germany, 2004, pp. 2192-2196. https://doi.org/10.1109/PESC.2004.1355460

[27] Tomlinson, M., du Toit Mouton, H., Kennel, R., Stolze, P. "A Fixed Switching Frequency Scheme for Finite-Control-Set Model Predictive Control—Concept and Algorithm", IEEE Transactions on Industrial Electronics, 63(12), pp. 7662-7670, 2016. https://doi.org/10.1109/TIE.2016.2593997

[28] Falkowski, P., Sikorski, A. "Finite Control Set Model Predictive Control for Grid-Connected AC-DC Converters With LCL Filter", IEEE Transactions on Industrial Electronics, 65(4), pp. 2844-2852, 2018. https://doi.org/10.1109/TIE.2017.2750627

[29] Panten, N., Hoffmann, N., Fuchs, F. W. "Finite Control Set Model Predictive Current Control for Grid-Connected Voltage-Source Converters With LCL Filters: A Study Based on Different State Feedbacks", IEEE Transactions on Power Electronics, 31(7), pp. 5189-5200, 2016. https://doi.org/10.1109/TPEL.2015.2478862

[30] Babqi, A. J., Etemadi, A. H. "MPC-based microgrid control with supplementary fault current limitation and smooth transition mechanisms", IET Generation, Transmission \& Distribution, 11(9), pp. 2164-2172, 2017. https://doi.org/10.1049/iet-gtd.2016.1387

[31] Hu, J., Zhu, J., Lei, G., Platt, G., Dorrell, D. G. "Multi-Objective Model-Predictive Control for High-Power Converters", IEEE Transactions on Energy Conversion, 28(3), pp. 652-663, 2013. https://doi.org/10.1109/TEC.2013.2270557

[32] Cortés, P., Rodríguez, J., Quevedo, D. E., Silva, C. "Predictive Current Control Strategy With Imposed Load Current Spectrum", IEEE Transactions on Power Electronics, 23(2), pp. 612-618, 2008. https://doi.org/10.1109/TPEL.2007.915605

[33] Babqi, A. J., Yi, Z., Etemadi, A. H. "Centralized finite control set model predictive control for multiple distributed generator smallscale microgrids", In: North American Power Symposium (NAPS), Morgantown, WV, USA, 2017, pp. 1-5. https://doi.org/10.1109/NAPS.2017.8107324

[34] Xia, C., Liu, T., Shi, T., Song, Z. "A Simplified Finite-ControlSet Model-Predictive Control for Power Converters", IEEE Transactions on Industrial Informatics, 10(2), pp. 991-1002, 2014. https://doi.org/10.1109/TII.2013.2284558 